\title{
A VEHICLE ROUTING PLANNING SYSTEM FOR GOODS DISTRIBUTION IN URBAN AREAS USING GOOGLE MAPS AND GENETIC ALGORITHM
}

\author{
Teodor Dimitrov Berov ${ }^{1}$ \\ ${ }^{1}$ Todor Kableshkov University of Transport, Faculty of Transport Management, Sofia, Bulgaria
}

Received 18 February 2016; accepted 4 April 2016

\begin{abstract}
This article presents a system aimed at generating optimized vehicles routes - the vehicle routing problem with time windows (VRPTW) based on using a Google Maps ${ }^{\text {"w }}$ network data and imperialist competitive algorithm meta-heuristic. The vehicle routing problem with time windows is an important problem in the supply chain management. It copes with route scheduling and the distribution of goods from the distribution center to geographically dispersed customers in urban areas by a fleet of vehicles with constrained capacities. The system was tested for urban goods distribution in Sofia, Bulgaria - 35 retailers, warehouse, two types of vehicles (capacity) and a working day.
\end{abstract}

Keywords: VRPTW, imperialist competitive algorithm, Google maps, genetic algorithm.

\section{Introduction}

The transportation of goods in urban areas imposes considerable costs on the transport sectors of the economy as well as the environment. More efficient vehicle routing can improve a firm's competitive advantage, increase the efficiency of supplying public services, and reduce energy consumption, traffic congestion and air pollution, which are growing problems in many urban areas.

Broadly speaking, vehicle routing and scheduling problems (VRP) (Toth and Vigo, 2002) involve the optimum assignment and sequencing of a set of transportation orders to a fleet of vehicles, considering various operational constraints. Such constraints have particular importance in those reallife settings where the vehicle fleet is heterogeneous, i.e., vehicles differ in their equipment, capacity, age or cost. Formally, the Heterogeneous Fleet Vehicle Routing Problem with Time Windows (HFVRPTW) involves the design of a set of minimum cost routes, each originating and terminating at the depot, using a heterogeneous fleet of vehicles with fixed and variable costs, to service a set of customers with known demands. Each customer must be serviced only once, within a predefined time window, by exactly one vehicle, while the total demand of a route must not exceed the capacity of the vehicle type assigned to it.

The use of a heterogeneous fleet of vehicles has multiple advantages (Paraskevopoulos et al., 2008). The scheduler can revise the fleet composition to better suit customer needs because they may require vehicles with expensive equipment. It is also possible to service customers requiring small vehicles because of accessibility restrictions in urban areas, environmental concerns or physical

\footnotetext{
${ }^{1}$ Corresponding author: tberov@vtu.bg
} 
restrictions on the vehicle size and weight. Furthermore, vehicles of different carrying capacities give the flexibility to allocate capacity according to the customer's varying demand, in a more cost effective way, by deploying the appropriate vehicle types to areas with the analogous concentration of customers. The distribution cost of a vehicle derives from the sum of its fixed cost and a variable cost proportional to the distance travelled.

The practical applications of the VRPTW include deliveries of goods to department stores, school bus routing, newspaper, mail distribution, maintenance services, etc. Traffic congestion forms a major problem for businesses (logistics service providers and distribution firms). Due to temporary traffic congestion, vehicles arrive late at customers and driving hours regulations are violated (Hari et al., 2014). Therefore, calculating variable cost proportional to the distance travelled and real travel time measured by real urban street network (incorporating Google Maps $^{\text {mt }}$ ), is necessary for the model VRPTW. By incorporating Google Maps ${ }^{\mathrm{m}}$, the final solution accommodates realistic system specifics, such as vehicle capacity and shift time constraints, as well as network constraints such as one-way streets and prohibited turns.

Ever since then the VRPTW put forward, many methods have been developed for solving it. This paper focuses on using the meta-heuristic to solve the VRPTW Imperialist competitive algorithm (ICA) (Atashpaz-Gargari and Lucas, 2007) which is inspired by imperialistic competition. According to the author, this is an evolutionary algorithm for optimization that has recently been introduced for dealing with different optimization tasks.
This evolutionary optimization strategy has shown great performance in both convergence rate and better global optima achievement. However, it is currently extensively investigated because of its effectiveness, limitations and applicability in various domains.

\section{Problem Description}

The theme of the proposed material is a method of planning the routes of commercial vehicles, with the aim of distributing the commodity cargo streams in urban areas, through taking into account the restrictions on movement and the specific requirements of the customers.

The model used for the supply of goods in the urban area, is a dynamic graph that mimics the changing of bandwidth usage on the streets, the presence of streets with one-way traffic, permanent and temporary bans for a U-turn, an increase of the traveled time on the route of overcoming slopes connected with the need to stop and the subsequent increase in speed. Under the conditions of dynamic graph, target function must be balanced between the traveled distance and the traveled time of the routes concerned.

These expectations determine the usable technologies. In this paper, the Google's web map service is used because it is one of the most widely used mapping service on earth and it provides a complete opensource programming API. According to the Google Maps API Terms recommended, the service can be available via Javascript programming language (Google Maps JavaScript API). Authors' choice is the C\# programming language, because it is done a Desktop program. 


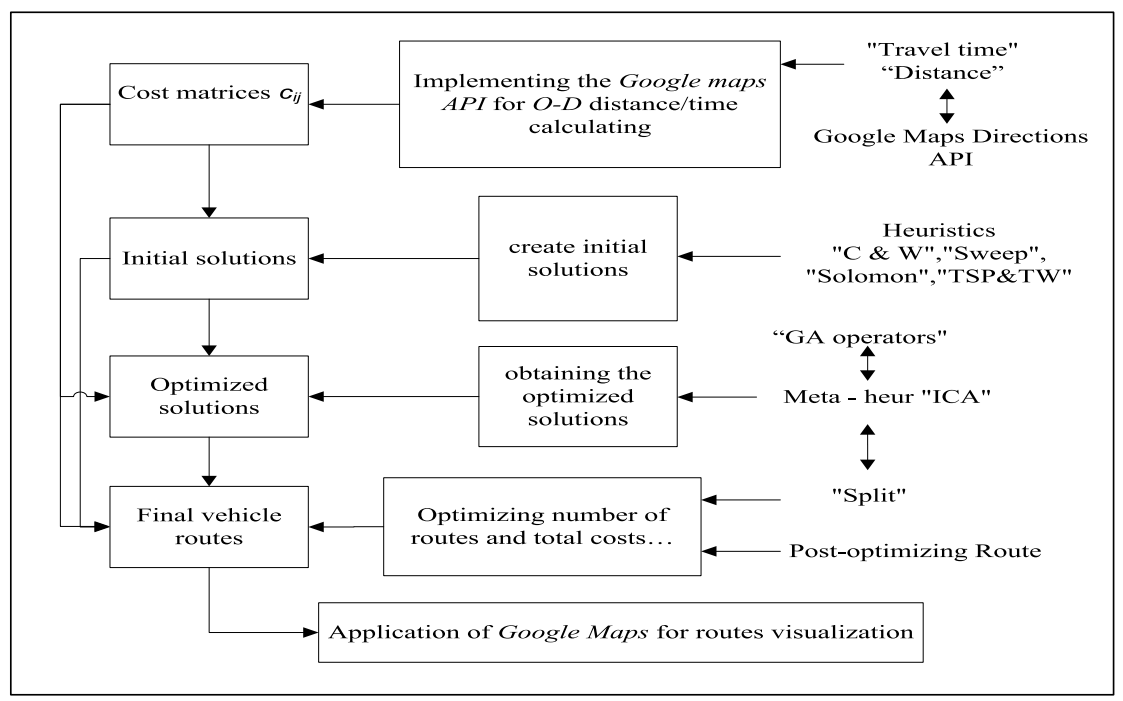

Fig. 1.

Component Diagram of the Proposed Framework

Fig. 1 depicts the main idea of the application of Google Maps API and GA.

Several techniques have been proposed for solving the vehicle routing problem with time window problem. Ever since then the VRPTW put forward, many methods have been developed for solving it (NEO/ VRP). An idea, that is used in some Genetic (population) algorithms (GA) where each chromosome is encoded as a giant tour (T) and Split is used again to evaluate giant tours (Split extracts the best VRP solution, subject to (T)). This is done by generating optimal shortest path within an auxiliary graph built from the giant tour. The chromosome is a permutation of $n$ positive integers, such that each integer is corresponding to a customer without trip delimiters. A chromosome may be broken into several different routes. Based on a literature review, widely used is Splitting algorithm (Christophe et al., 2010; Prins, 2004). Because a chromosome can be split into many different routes, author proposed a splitting procedure which can find an optimal splitting, i.e. a trip delimiter so that the total cost is minimized.

In all these algorithms, new chromosomes are generated using either by crossover or by mutation procedures. Needed are a sufficient number of initial solutions, especially for the crossover procedure. The qualitative initial variants have significant influence on the quality of the final result.

A flow diagram of the proposed algorithm is shown in Fig. 2.

Application of ICA (Atashpaz-Gargari and Lucas, 2007)

As mentioned in section 1, the goal is to find the best solution (number of vehicles and their routes to service client requests, taking into account restrictive conditions), with minimal total cost, i.e. min. problem. 
The Fitness function for Vehicle Routing with time windows problems can be explained as Eq. (1):

$C(S)=\sum_{i=1}^{n} C\left(R_{i}\right)$

$\rightarrow \min$

A solution $S$ is a collection of routes, $R_{1}, R_{2} \cdots$ $R_{l}$, such that each customer will be covered by exactly one route $R_{i}$.

In this case, an individualist, "country", is the sequence of objects for service (an array of integer values), country $=\left[v_{1}, \ldots, v_{n}\right]$. The best country country ${ }^{*}$ is defined as: country ${ }^{*}=\left[v_{1}, \ldots\right.$, $\left.v_{n}\right]^{*}=\min \left\{\operatorname{cost}(\text { country })_{\mathrm{i}}\right\}$, i.e. minimum value of the objective function $C(S)$, Eq. (1).

To perform the steps envisaged to ICA Imperialistic competition, it is necessary to determine the Total Power of an Empire in regard to the VRP.

Total Power of an Empire is mainly affected by the power of imperialist country. The power of the colonies of an empire has an effect of increase on the total power of that empire. For VRP, the most powerful imperialist country is the one with the smallest value of the objective function (Karagyozov and Berov, 2014). ICA determines the total power of an empire based on the total cost $\left(T C_{n}=\right.$ Cost (imperialist $\left.{ }_{n}\right)+\varepsilon$ mean $\{$ Cost (colonies of empire $\left.\left._{n}\right)\right\}$ ). Because the problem is minimized, total cost will be determined by "savings", i.e. the difference between the cost of worst individualist (country) of all existing empires and current:

$S C_{n}=\max \left\{C_{i j}\right\}-C_{n}, i=1 \ldots N_{i m p}, j=1 \ldots N_{i}(c o l)$

Total cost of $n$-th Empire:

$T C_{n}=S C\left(\right.$ imperialist $\left._{n}\right)+\varepsilon$ mean $\left\{S C\left(\right.\right.$ colonies of empire $\left.\left._{n}\right)\right\}$

Where $T C_{n}$ is the total cost of $n$-th Empire and $\varepsilon$ is a positive number $0<\varepsilon<1$. 


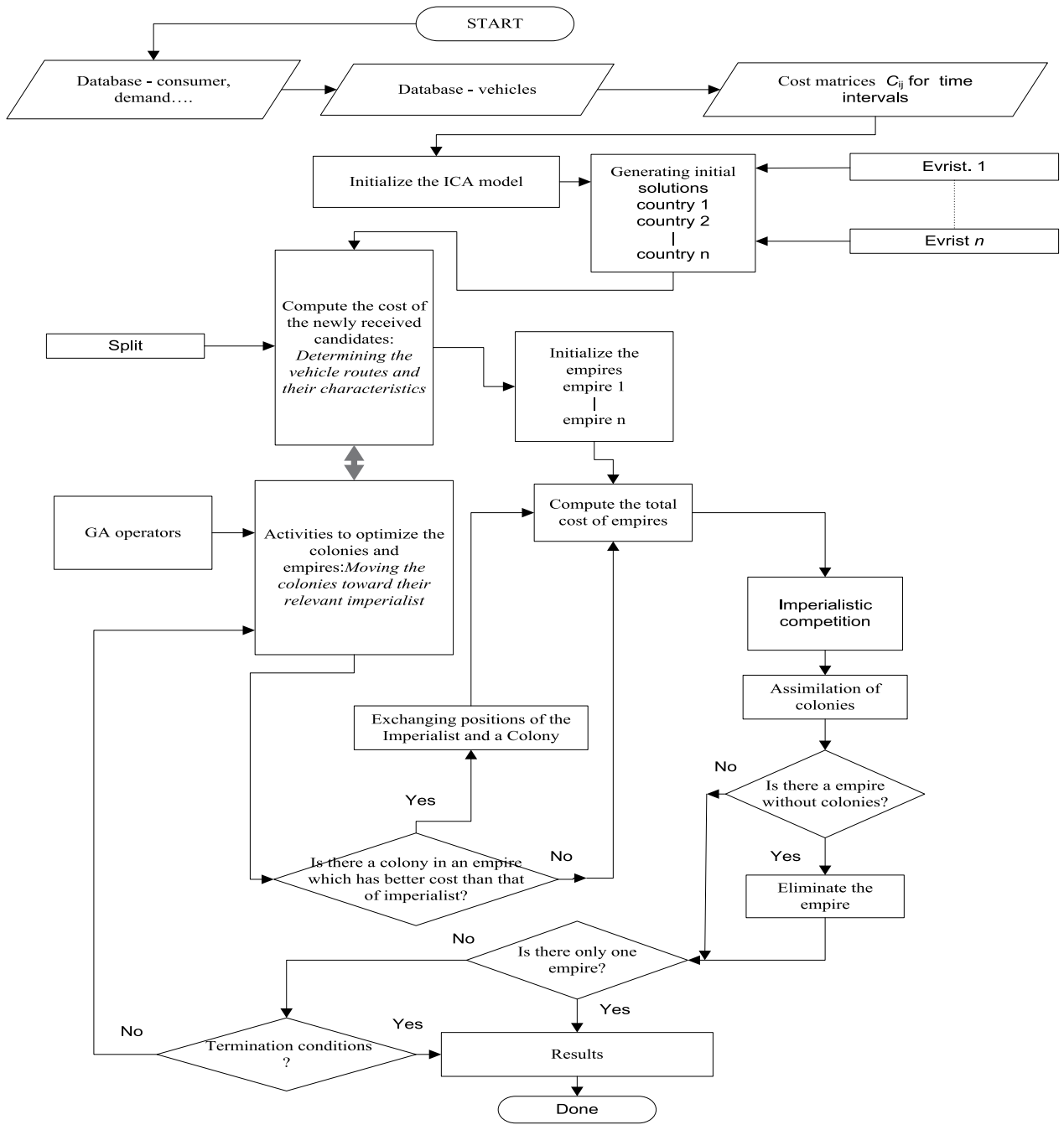

Fig. 2.

Flow Chart for the System 


\subsection{Determining the Parameters of the Serviced Customers, Urban Area and the Traffic}

For Real-World VRP applications setup step includes defining service/operation type, planning horizon, demand type and size, available resource set, start and end locations for the route, service times at locations (Todorova and Djaleva, 2014). These are discussed in detail below.

Planning horizon: is a single day.

Truck capacity: volume and weight; Cost per hour and cost per kilometer.
Time period: 1, Morning Peak Period; 2, Inter-peak; 3, Afternoon Peak Period.

Breaks: After driving at most 4.5 hours, the truck driver must take a break of at least 0.5 hours. The driving hours regulations do not allow service time at customers to be considered as break time.

Service time For Customers: First of all, it is necessary to define the stop time at each visited location. Stop times depends on several factors: number of products and size; the presence and type of loading dock; vehicle type and others. The parameters depend especially from Time period $(\tau)$ and Demand size $\left(d_{i}\right)$ (Table 1$)$.

Table 1

Parameters for Calculating the Stop Time at Each Visited Location

\begin{tabular}{|l|c|l|l|l|l|}
\hline \multicolumn{2}{|l|}{ Parameters and variables } & \multicolumn{2}{l|}{ Parameters and variables } & \multicolumn{2}{l|}{ Parameters and variables } \\
\hline $\begin{array}{l}\text { Parking search time, } \\
(\tau)\end{array}$ & $t_{i}^{\text {park. }}(\tau)$ & $\begin{array}{l}\text { Check the order and } \\
\text { processing }\end{array}$ & $t_{i}^{\text {ch }}$ & Load/unload time, $\left(d_{i}\right)$ & $t_{i}^{\text {lu }}\left(d_{i}\right)$ \\
\hline $\begin{array}{l}\text { Preparation of the } \\
\text { order }\end{array}$ & $t_{i}^{\text {po }}$ & Waiting-time (tail), $(\tau)$ & $t_{i}^{\text {tail }}(\tau)$ & & \\
\hline
\end{tabular}

$t_{i}^{s t}=t_{i}^{\text {park }}(\tau)+t_{i}^{\text {po. }}+t_{i}^{l u}\left(d_{i}\right)+t_{i}^{c h}+k_{i}^{o \sigma} \cdot t_{i}^{\text {tail }}(\tau), \min$

Waiting-time tail, depending on the number of orders in tail $n$ :

$t_{i}^{\text {tail }}=\frac{t_{i}^{\text {lu.mean }}+t_{i}^{\text {ch.mean }}}{2}+(n-1) \cdot\left(t_{i}^{\text {lu.mean }}+t_{i}^{\text {ch.mean }}\right), \min$

Table 2

Parameters for the Vehicles

\begin{tabular}{|l|l|l|l|l|l|l|l|}
\hline \multirow{2}{*}{ № } & \multirow{2}{*}{ Vehicles } & \multicolumn{2}{|l|}{ Capacity } & \multirow{2}{*}{ Emission factor } & Num. & $\begin{array}{l}\text { F.cost, } l v / \\
\text { day }\end{array}$ & V.cost, $l v / k m$ \\
\cline { 3 - 4 } & & $\mathbf{t}$ & $\mathbf{M}^{3}$ & & & \\
\hline 1 & Tip A & 1,5 & 8,0 & EURO IV & 10 & 92,58 & 0,35 \\
\hline 2 & Tip B & 3,4 & 12,5 & EURO V & 2 & 152,30 & 0,47 \\
\hline
\end{tabular}




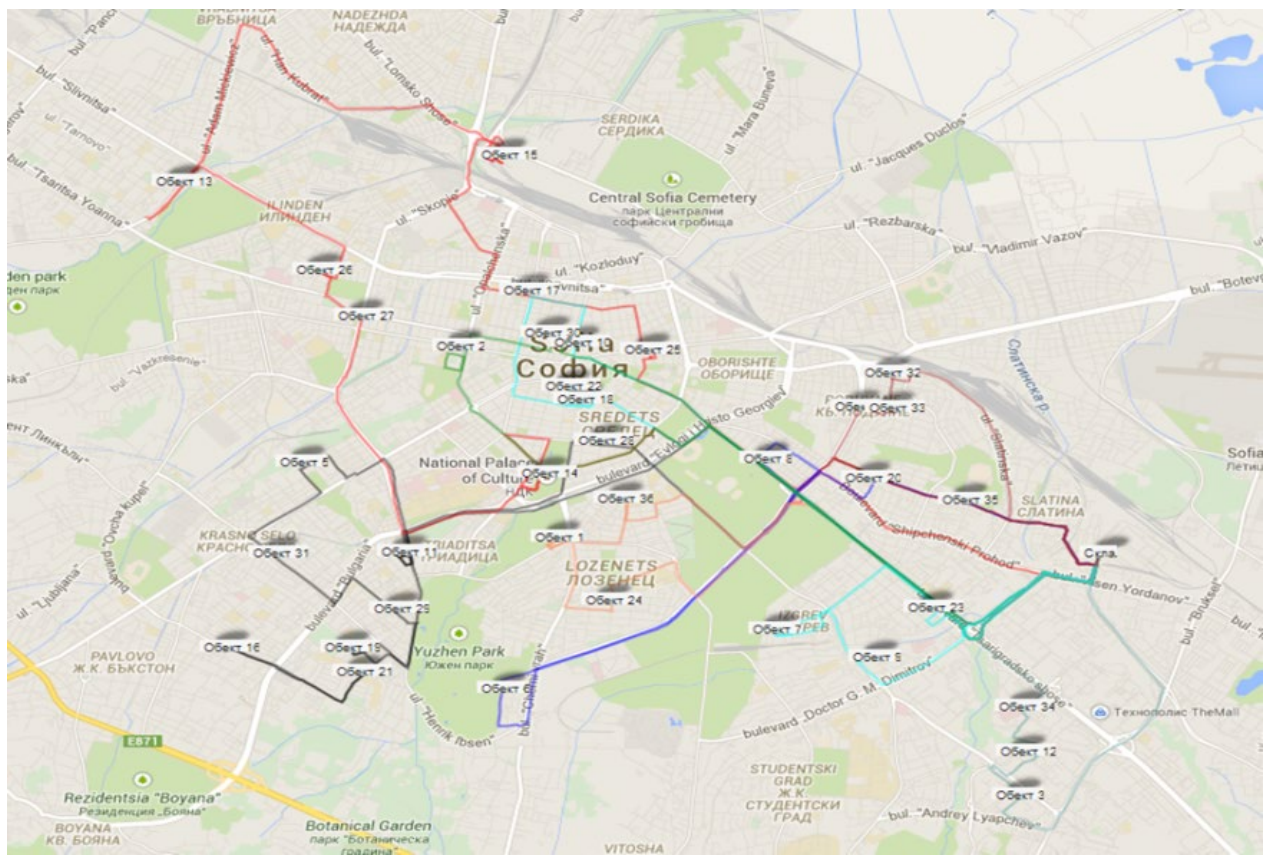

Fig. 3.

Route of all Vehicles

\subsection{Application of the Proposed Algorithm}

Through this work we seek to optimize the routing decisions for ready outbound vehicles at a dispatching center (i.e. the depot, 35 stores located in Sofia). Location of objects on the map of the city is shown in Fig. 3. The TW for the consumers are soft, but in the simulation they are used like hard. For some consumers, located in the city center, there is a limit to the load capacity of the vehicle. The results are shown in the Fig. 3 and the following Table 3.

Table 3

Routing Result

\begin{tabular}{|c|c|c|c|c|c|c|c|c|c|}
\hline \multirow{2}{*}{ Rout } & \multirow{2}{*}{ Distance $\mathrm{km}$} & \multirow{2}{*}{ Duration $h$} & \multirow{2}{*}{ Visited cust. } & \multirow{2}{*}{$\begin{array}{l}\text { Load } \\
t\end{array}$} & \multirow{2}{*}{$\begin{array}{l}\text { Start R. } \\
+t_{\text {startTW }} \min \end{array}$} & \multirow{2}{*}{$\begin{array}{l}\text { Wait TW } \\
+t_{\text {waitTW }} \text { min }\end{array}$} & \multicolumn{3}{|c|}{ Durations, $h$} \\
\hline & & & & & & & $t_{\text {driving }}$ & $t_{\text {stop }}$ & $t_{\text {park }}$ \\
\hline M3-01 & 30,50 & 5.17 & 9 & 3,206 & 0 & 0 & 1.84 & 3.33 & 0.70 \\
\hline M3-02 & 34,60 & 5.00 & 7 & 3,278 & 0 & 0 & 2.02 & 2.98 & 0.58 \\
\hline M3-03 & 17,70 & 2.32 & 3 & 1,387 & 46 & 0 & 1.00 & 1.32 & 0.23 \\
\hline M3-04 & 16,40 & 2.05 & 3 & 1,399 & 8 & 0 & 0.97 & 1.08 & 0.20 \\
\hline M3-05 & 17,50 & 2.52 & 3 & 1,400 & 10 & 0 & 1.05 & 1.47 & 0.27 \\
\hline M3-06 & 17,90 & 1.73 & 2 & 1,332 & 0 & 0 & 0.93 & 0.80 & 0.15 \\
\hline M3-07 & 9,70 & 2.07 & 3 & 1,448 & 0 & 0 & 0.74 & 1.33 & 0.23 \\
\hline M3-08 & 9,80 & 1.83 & 3 & 1,313 & 14 & 0 & 0.70 & 1.13 & 0.23 \\
\hline M3-09 & 8,50 & 1.73 & 3 & 1,323 & 136 & 11 & 0.61 & 1.12 & 0.22 \\
\hline Sum & 162.6 & 24.42 & 36 & 16.086 & 214 & 11 & 9.86 & 14.56 & 2.81 \\
\hline
\end{tabular}




\section{The assignment of routes to vehicles}

The estimated routes duration (Table 3 ) is used to optimize the use of vehicles:

- $\quad$ ПС1-M3-01;

ПС2-М3-02; ПС3-М3-06, М3-09; ПС4-M3-04, М3-07;

- $\quad$ ПС5 - M3-03;

ПС6 - М3-05; ПС7- М3-08.

\section{Performance parameters for vehicles and working day}

The results are shown in the following Table 4.

\section{Table 4}

The Result for Vehicles for Working Day

\begin{tabular}{|c|c|c|c|c|c|c|c|c|}
\hline ПС & $\begin{array}{l}\text { Distance } \\
\mathrm{km}\end{array}$ & $\begin{array}{l}\text { Duration } \\
h\end{array}$ & $\begin{array}{l}\text { Load } \\
t\end{array}$ & Routs & Visited & $\begin{array}{l}\text { Fixed cost } \\
l v\end{array}$ & $\begin{array}{l}\text { Variable cost } \\
l v\end{array}$ & $\begin{array}{l}\text { Payload- } \\
\text { distance } \\
t . \mathrm{km}\end{array}$ \\
\hline ПС1 & 30,50 & $\begin{array}{l}5,67 \\
(+0,5 \text { rest. })\end{array}$ & 3,206 & 1 & 9 & 152.30 & 14.03 & 51.81 \\
\hline ПС2 & 34,60 & $\begin{array}{l}5,50 \\
(+0,5 \text { rest. }) \\
\end{array}$ & 3,278 & 1 & 7 & 152.30 & 15.92 & 67.13 \\
\hline ПС 3 & 28,40 & 3,46 & 2,655 & 2 & 5 & 92.58 & 9.94 & 14.78 \\
\hline ПС4 & 26,10 & 4,12 & 2,841 & 2 & 6 & 92.58 & 9.14 & 19.09 \\
\hline ПС5 & 17,70 & 2,32 & 1,387 & 1 & 3 & 92.58 & 6.20 & 16.64 \\
\hline ПС6 & 17,50 & 2.52 & 1,400 & 1 & 3 & 92.58 & 6.13 & 11.54 \\
\hline ПС7 & 9,80 & 1.83 & 1,313 & 1 & 3 & 92.58 & 3.43 & 7.25 \\
\hline Sum & 162.6 & 25.42 & 16.086 & 9 & 36 & 767.50 & 64.77 & 188.24 \\
\hline
\end{tabular}

Table 5

Schedule of Vehicles

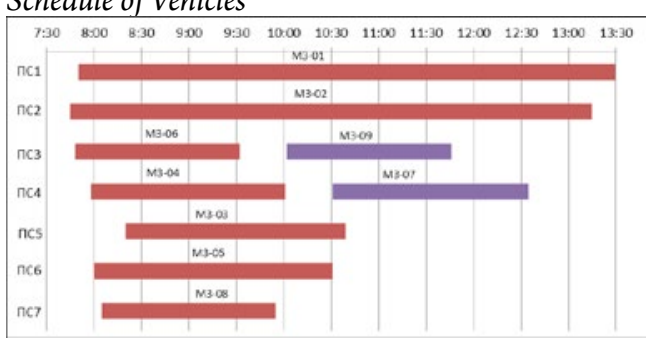

\section{Conclusion}

In this paper, the focus is on aRP with time windows and different travel times, taking into account the different time intervals. The aim is to construct reliable and efficient routes by means of the realistic travel distances and times for urban street network. The proposed model used combinations of the logistic costs with respect to the carrier companies' priorities.

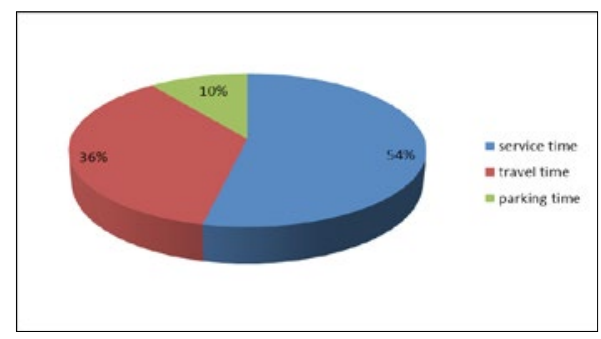

Fig. 4.

Time Distribution

In real-life applications, it is important to consider time-dependent travel times since speeds vary throughout the day due to the events like accidents or congestion during the rush hours. In this system, the detailed street/road network data is managed by Google Maps. This makes it possible to consider the problems presented by densely built-up areas. As mentioned at the beginning of the paper, the target of the study can be regarded a variety urban freight transport. 
Additionally, a metaheuristic procedure - ICA is proposed. The metaheuristic procedure behaves effectively for problems with heterogeneous fleet because the ruin step systematically allows for the frequent combination of two or more routes into a longer route requiring a larger vehicle and the splitting of a given route into a few smaller routes.

\section{References}

Atashpaz-Gargari, E.; Lucas, C. 2007. Imperialist competitive algorithm: an algorithm for optimization inspired by imperialistic competition, IEEE Congress on Evolutionary Computation, 4661-4667.

Christophe, D. et al. 2010. A GRASPxELS with Depth First Search Split Procedure for the HVRP, Research Report LIMOS/RR-10-08.

Google Maps JavaScript API. Available from Internet: <https://developers.google.com/maps/documentation/ javascript/>.

Hari, S.; Gangesh, M.; Kamal, P. 2014. GIS Based Solution of Multi-Depot Capacitated Vehicle Routing Problem with Time Window Using Tabu Search Algorithm, International Journal for Traffic and Transportation Engineering, 3(2): 83-100.
Karagyozov, K.; Berov, T. 2014. Prilozhenie na imperialisticheski konkurenten algoritam za optimizirane marshrutizatsiyata na prevoznite sredstva, Mehanika, transport, komunikatsii, 3(1): 6368. (In Bulgarian: Карагьозов, К.; Беров, Т. 2014. Приможение на империалистически конкурентен алгоритъм за оптимизиране маршрутизацията на превозните срелства, Механика, транспорт, комуникации, 3(1): 63-68.)

NEO/VRP. Available from Internet: <http://neo.lcc. uma.es/vrp/>.

Paraskevopoulos, D.C. et al. 2008. Reactive Variable Neighborhood Tabu Search for Heterogeneous Fleet Vehicle Routing and Scheduling Problems, Journal of Heuristics, 14(5): 425-455.

Prins, C. 2004. A simple and efective evolutionary algorithm for the vehicle routing problem, Computer and Operations Research, 31(12): 1985-2002.

Todorova, M.; Djaleva, A. 2014. Za menidjarite v tovarnija avtomobilen transport, Sofia. (In Bulgarian: Тодорова, М.; Ажамева, А. 2014. За мениджърите в товарния автомобилен транспорт, София.)

Toth, P.; Vigo, D. 2002. The Vehicle Routing Problem (Eds.), SIAM Monographs on Discrete Mathematics and Applications, Philadelphia. 